\title{
História, crime e cultura de massa
}

\author{
Entrevista com Dominique Kalifa*
}

Em agosto de 2009, Dominique Kalifa, professor da Universidade de Paris 1 e diretor do Centre d'Histoire du XIXème Sciècle, esteve no Instituto de Filosofia e Ciências Sociais, a convite do Programa de Pós-graduação em História Social da Universidade Federal do Rio de Janeiro (PPGHIS/UFRJ). $\mathrm{O}$ historiador francês concedeu, nesse mesmo momento, uma entrevista a professores do PPGHIS em torno das questóes que marcam o seu trabalho sobre a história do crime e da cultura de massa.

Topor: Como fazemos uma entrevista para um público que talvez náo o conheça, que tal começarmos por um panorama de sua trajetória intelectual e de sua carreira acadêmica?

D. Kalifa: Penso que o mais importante é dizer que sempre procurei conciliar uma história social, que continua, na minha concepção, a ser o coração da história — o social como interação dos indivíduos e como produção que uma sociedade pode ter de si própria - com a história cultural, pensada como história das representaçóes. Enquanto uma grande parte dos debates históricos atuais quer criar um fosso entre história cultural e história social, eu fiz e continuo fazendo de tudo para imaginar o cultural como um instrumento, uma entrada para fazer história social. Eu me recuso absolutamente a dissociar história social e história cultural. Digo isso para explicar por que fui procurar uma historiadora como Michelle Perrot, que vem da história social tradicional, para ser minha orientadora. ${ }^{1}$ Sua tese tratava de operários em greve, em uma percepção bastante clássica da história social. Quando, há muito tempo, fui falar com ela para um trabalho sobre as representaçóes do crime - mais precisamente o crime na literatura, que era minha primeira ideia —, eu não quis dizer-lhe que, se eu fazia história do crime, era para Arsène Lupin. Eu o adoro, ele era a minha motivaçáa inicial. Mas, se fui falar com Michelle Perrot sobre um projeto acerca do crime na literatura, o crime nos jornais, o crime na cultura, foi também porque eu queria que minhas reflexóes tivessem um sentido social e que essa interrogaçáo sobre as representaçôes pudesse desembocar em uma história social. Acredito que, desde entáo, sempre utilizei as representaçóes sociais como instrumento de conhecimento de uma sociedade e das relaçóes entre os homens. Na França, os dois historiadores que mais me marcaram foram, de um lado, Michelle Perrot, por seu trabalho sobre a história social, a história da prisão, da marginalidade, da criminalidade, que, na esteira de Foucault, ela inventou, como inventou também a cultura dessas questóes na França; e, de outro lado, Alain Corbin, com quem eu trabalhei mais tarde, e que pediu que eu o sucedesse na Universidade de Paris I. Alain Corbin é visto antes como um historiador da cultura e das representaçôes, mas também vem da história social tradicional — sua tese era uma história social de Limoges ou do Limousin no século XIX ${ }^{2}$ - e sempre se preocupou em utilizar representaçóes e sensibilidades

\footnotetext{
* Dominique Kalifa foi entrevistado em 1ํ de agosto de 2009 no Programa de Pós-graduação em História social da Universidade Federal do Rio de Janeiro (PPGHIS/UFRJ) por Marcos Luiz Bretas (mlbretas@gmail.com, PPGHIS/UFRJ) e Diego Galeano (dgaleano.ufrj@gmail.com, PPGHIS/UFRJ). Transcrição de Amaury Leibig van Huffel e tradução de Raquel Campos.

${ }^{1}$ A tese de doutorado em história na Universidade de Paris-VII, orientada por Michelle Perrot e defendida em 1994, foi publicada em: KALIFA, Dominique. L'encre et le sang. Récits et société à la Belle Époque. Paris: Fayard, 1995.

${ }^{2}$ CORBIN, Alain. Archaïsme et modernité en Limousin au XIXe siècle, 1845-1880. Paris: Marcel Rivière, 1975. 2 v.
} 
como uma entrada para a história social. Meus objetos — o crime, a justiça, a cultura de massa — são diferentes dos dele, mas, em minha trajetória acadêmica, muito influenciada por esses dois historiadores, sempre me preocupei em cruzar a história das representaçôes e a história das produçôes sociais, das interaçôes sociais, seguindo essa ideia de Marc Bloch e Lucien Febvre, os autores dos Annales, segundo a qual não há história senão social — mesmo que as vias ou os instrumentos para lê-la, ou para chegar até ela, sejam diferentes. $\mathrm{Na}$ história dos faits divers, na do romance policial, na da polícia privada, na dos criminosos, na da cultura de massa ou, mais recentemente, no trabalho sobre os presídios militares eu busquei sempre essa entrada. Outro tema que pode ser mencionado para responder a essa questáo da trajetória intelectual é o do imaginário social. O que é um imaginário social? É o conjunto das produçôes, ficcionais ou não, que podem produzir uma concepçáo, uma representaçáo da sociedade, e que será produtora de práticas sociais. A ideia de representação social, tal como concebida por Durkheim, consiste exatamente nisso: são representações constitutivas do social, matrizes da sociedade. $\mathrm{O}$ trabalho sobre os faits divers, sobre os romances, sobre a cultura de massa, está sempre em busca das representações constitutivas de práticas sociais.

Topor: Você se referia a estes aportes dentro da história cultural. Parece-me que sua trajetória mostra como, em particular, a história cultural das representaçóes do crime parece conduzir, inevitavelmente, a uma história da gênese da cultura de massa. Ainda temos o problema cronológico dos pensadores de Frankfurt que localizavam essa gênese no século XX. A pergunta é: em que medida a historiografia recente, que se ocupa das narrativas, das representaçóes da questâo criminal, trouxe novos elementos para os estudos sobre consumo maciço de bens culturais? Para reformular a pergunta: em que medida estes dois campos - a história das representaçóes do crime e o campo mais geral da cultura de massa - se entrelaçam?

D. Kalifa: Eu gostaria, em primeiro lugar, de dizer algumas palavras sobre a primeira parte da questão, a respeito dos problemas de periodização da cultura de massa. É verdade que, nos últimos dez anos, assistimos na França a uma reconfiguração completa das periodizaçôes e a uma rejeição das posiçôes tradicionais de Adorno, Horkheimer ou Benjamin, ou ainda de Krakauer, sobre a datação da cultura de massa entre a Primeira e a Segunda Guerra Mundial. O problema está no conceito "massa" - , que, como o conceito de povo, é extremamente ideológico, funcionando segundo uma perspectiva ou alarmista — as massas como elemento de embrutecimento, de nivelamento, de demissão do pensamento crítico - , ou das massas como esperança, como esperança revolucionária, mas em ambos os casos associa-se o dispositivo cultural à existência de massas. Ora, em 1900, ou em 1880, ou em 1860, ou mesmo em 1836, as massas não existiam. Acredito que os trabalhos mais interessantes - e penso aqui em dois colegas literatos, Alain Vaillant e Marie-Ève Thérenty, que escreveram um belíssimo livro intitulado 1836, o ano I da era mediática, ${ }^{3}$ e também em vários outros sociólogos sejam os que procuram pensar, não a cultura de massa, mas a cultura midiática ou as mídias culturais, segundo os termos de dois sociólogos, Eric Maigret e Eric Macé; quer dizer, que propóem dissociar o funcionamento de um aparelho de produçáo cultural e o público de massa. Alain Vaillant mostra que, entre 1825 e 1836, o funcionamento da imprensa na França subverte radicalmente a concepção tradicional do papel dos jornais - ao passo que, evidentemente, nessa época, não há público de massa. Ele demostra que se passa de um dispositivo argumentativo, retórico nos jornais — dispositivo, portanto, da imprensa doutrinária - a um dispositivo de representação, segundo o qual a imprensa deve deixar de ser argumentativa para se tornar representativa, isto é, representar a sociedade em suas

\footnotetext{
${ }^{3}$ VAILLANT, Alain; THÉRENTY, Marie-Éve. 1836: l’an I de l’ère médiatique, étude littéraire et historique du journal La Presse, d'Emile de Girardin. Paris: Éditions du Nouveau Monde, 2001.
} 
diversas componentes, utilizando, para isso, a narrativa; uma imprensa, portanto, representativa e narrativa. E, nessas condiçóes, percebemos que as mudanças principais não ocorrem em 1930 ou mesmo em 1900, mas sim nas décadas de 1830, 1840, quando se estabelece um novo dispositivo, embora não haja público de massa. Em outras palavras, a oferta cultural é, em relação a isso, mais importante que a demanda, porque ela vai constituir uma mecânica que, progressivamente, carrega consigo também a própria demanda. Então, continuo pensando que as principais mudanças culturais que produzirão aquilo que chamamos de "cultura de massa" situam-se em meados do século XIX, embora o número de leitores, de consumidores ainda não seja maciço. "As massas" ainda não existem, mas o paradigma da representaçáo social voltada para o maior número de pessoas é estabelecido fundamentalmente nessa época. Em relação ao lugar do crime nesse paradigma, eu gostaria de sublinhar duas coisas: em primeiro lugar, o crime era um motivo tradicional, de longa data, de representação popular, desde os jornais ocasionais do Antigo Regime, as folhas avulsas, os panfletos. Há na literatura de colportagem um interesse popular pela transgressão, pela ruptura social, que é extremamente importante e que reencontraremos quando os jornais de grande tiragem recuperarem esse imaginário. A segunda questáo é que o crime é um acontecimento histórico popular; ele é esse fato que ocorre de repente na vida das pessoas ordinárias, suscitando nelas o inesperado, o extraordinário, o acontecimento - o histórico, portanto. Daí resulta que essas histórias de crime, que são tradicionais e que serão veiculadas por um dispositivo editorial cada vez mais maciço, são também histórias que contam às pessoas ordinárias, aos leitores ordinários, qualquer coisa de suas próprias vidas, de suas próprias histórias. Parece-me que uma das principais características da cultura de massa seja transformar, progressivamente, o leitor, o espectador, no objeto mesmo do consumo cultural. Trata-se de uma cultura autofágica, que faz do consumo de nós mesmos o coração de sua produção, sendo, por isso, uma cultura democrática no primeiro sentido do termo. Nós nos consumimos. Observem o cerne da televisão contemporânea, que, por meio do sistema dos reality-shows, estabeleceu o espetáculo banal, ordinário, medíocre, trivial... de nós mesmos. Alguma coisa da mesma natureza — autocentrada, autofágica — se passa com o crime. Essas histórias criminais sáo histórias ordinárias, que podem acontecer com gente ordinária, portanto, com os consumidores da cultura de massa, que são, ao mesmo tempo, os leitores e os objetos do consumo cultural. Eu acredito, então, que não sejam simplesmente duas histórias superpostas, penso que a questão do crime, ou, para dizer mais amplamente, a ruptura da norma banal — pois isso vale também para os acidentes e os acontecimentos extraordinários - , a constituiçáo desse excepcional banal seja fundamentalmente constitutiva da cultura de massa porque conta às pessoas suas próprias histórias, transformando, portanto, em ator completo o consumidor passivo, segundo a Escola de Frankfurt, da cultura de massa. Ora, ele não somente não é passivo, como se tornou o objeto mesmo de seu próprio consumo. É também o que a historiadora americana Vanessa Schwartz, em um livro interessante intitulado Spectacular realities: early masse culture in fin-de-siècle Paris, havia demonstrado. ${ }^{4}$ Aquilo que nós consumimos, o que a cultura de massa está consumindo e produzindo como acontecimento, é o espetáculo de nós mesmos: a loja de departamentos, a rua, o bulevar em cujo café nos instalamos para ver passar a nós mesmos... e o cinema também, no início, segue essa lógica. Mas, de certa maneira, é o fait divers, sem dúvida, e talvez principalmente o fait divers criminal que fazem do leitor ordinário, ao mesmo tempo, o objeto, o consumidor e o leitor de sua própria história transformada em história extraordinária. Então eu penso que é realmente consubstancial.

Topor: E, nesse sentido, parece que sua leitura da imprensa popular não só dialoga com algumas teorias da cultura de massa, como também com algumas teorias literárias e concepçóes dentro da crítica

${ }^{4}$ SCHWARTZ, Vanessa. Spectacular realities: early mass culture in fin-de-siecle Paris. Berkeley: University of California Press, 1998. 
literária. Penso, por exemplo, nas visões estruturalistas sobre os faits divers, ou inclusive as leituras sobre a figura do detetive. Você poderia desenvolver um pouco essas questóes?

D. Kalifa: Sim. Bom, como eu disse no início, sempre procurei associar história social e história cultural, mas isso subentende também um uso da literatura e das teorias literárias. A relação com o estruturalismo é complexa, porque é efetivamente a relação entre o que alguns estruturalistas - penso sobretudo na antropologia estrutural — pensaram como invariante - e o crime é pensado como tal e a dimensão histórica fundamental, que acredito que deva também ser recuperada. Então, tomo muito cuidado com certo número de literatos - Barthes, por exemplo, mas também com Lukács e com todas as teorias sobre as estruturas sociais da literatura - , porque é necessário considerar efetivamente o que os textos dizem e o que comportam, mas não só isso. Gosto do termo "cotexto", proposto por um historiador, um sociólogo da literatura francês que se chama Claude Duchet. "Cotexto", e não contexto, uma noçăo mais complexa e mais interessante, que diz respeito a tudo o que o texto literário implica, a tudo o que ele carrega consigo, a tudo o que se pode encontrar no texto, mas que não é o texto. Penso que essa seja uma noçáo importante. Eu fui bastante influenciado por essas teorias, ao mesmo tempo que permaneci fundamentalmente um historiador, quer dizer, alguém atento às variaçôes sociais de temas que são, às vezes, de longa duração, mas que variam socialmente de maneiras muito diferentes. A inflexão 1900, que procurei evidenciar em relação à constituição de uma problemática moderna da segurança, é nesse sentido típica: trata-se de uma temática muito tradicional, com motivos tão antigos quanto o crime e que, no entanto, pode dar ensejo a uma problemática nova. Essa é, então, a distância que é preciso manter em relaçáo à antropologia estrutural. Mas, por outro lado, guardo da literatura e das teorias literárias a ideia de que o texto não reflete nada. Sou muito hostil às teorias do reflexo, às teorias da mímesis. Um texto não reflete nada, ele exprime realidades que sáo, a cada vez, efetivamente diferentes e que colocam em relação, na maioria dos casos, níveis de representação - e não uma representação unívoca entre o que seria o texto literário e o que seria uma realidade. Um texto diz respeito a correspondências de níveis de representaçôes diferentes — o que torna a coisa mais complicada, mas também mais interessante.

Topor: Em geral, quando nós de países latino-americanos fazemos uma entrevista com um professor europeu, costuma-se pensar em termos da aplicabilidade dessas concepçóes, dessas teorias para pensar alguma problemática local. Procurando tomar esse campo, mas, de algum modo, contornando-o, recordo-me de um livro do Marc Bloch em que ele dizia que havia dois caminhos possíveis dentro da história comparada: primeiro, a possibilidade de trabalhar com fatos ocorridos em grupos, sociedades, culturas distantes no tempo e no espaço; e o segundo caminho consiste em trabalhar com experiências de influência mútua, de intercâmbios culturais, imanentes a essas sociedades que se está comparando. Digamos, para aqueles que trabalhamos, de alguma maneira, com a história cultural do crime, o que podemos fazer com isso, para além da mera constatação do caráter internacional destas narrativas? Como você crê que se possa orientar uma história transnacional do crime?

D. Kalifa: Pessoalmente, não sou favorável ao que chamo, para simplificar, de um "comparativismo de laboratório". Meu colega e amigo Christophe Charle, que é um dos principais historiadores a praticar o método comparativo, pensa - em uma perspectiva marcada mais pela sociologia, e sobretudo pela sociologia de Pierre Bourdieu — que relacionar situaçôes muito diferentes produz, conceitualmente, ganhos de inteligibilidade, afastamentos de sentido que permitem dar conta de forma mais apropriada das especificidades ou das singularidades e que, portanto, pode-se imaginar um comparativismo experimental, de laboratório, de certo modo, podendo-se comparar realidades que, à época, não tiveram possibilidades efetivas de serem comparadas. É uma perspectiva muito interessante, mas a minha é preferencialmente uma concepção compreensiva da história; penso que a história deva restituir a maneira 
segundo a qual os atores sociais percebiam, apreendiam e atribuíam sentido a seu próprio universo. Então, pessoalmente, não me reconheço nesse "comparativismo de laboratório". Por outro lado, acredito que seja extremamente interessante pensar as transferências culturais ou sociais; ver efetivamente como, quando os modelos circulam - isso é muito claro em matéria policial, mas também cultural e jornalística -, as proposiçôes são trabalhadas, adaptadas, ajustadas às condiçôes culturais locais. É como isso de que você falava, quer dizer, o modo como teremos Troppmann argentinos, ou Vidocqs brasileiros, ou modelos policiais pegos emprestados de Londres, de Paris. É isso o que é interessante. Em termos de história do crime e da polícia, pode-se esperar duas coisas de tais estudos de transferências. A primeira é ver aparecerem figuras bastante convergentes, bastante fortes e que teriam um sentido quase epistemológico. Penso, por exemplo, na figura do inquérito, que em vários livros procurei tornar evidente. Creio que na sociedade ocidental, em determinados momentos, surjam formas de questionamento do social, formas de produção de verdades sociais que eu denomino, para simplicar, o modelo do inquérito, os quais circulam extremamente rápido entre os países. Acredito, por exemplo, que é interessante revelar a existência do que podemos chamar de um paradigma do inquérito, nas sociedades ocidentais e para além delas, desde o final do século XVIII e no início do século XIX — uma perspectiva que é diferente da de Michel Foucault, porque, em suas análises em termos de épistémè, ele vê uma diferença muito grande entre o que ele denomina o paradigma da investigação, que teria terminado na passagem do século XVIII para o século XIX, e o do exame ou da vigilância, que seria próprio da sociedade disciplinar. Penso que o primeiro interesse dos trabalhos sobre transferências seja mostrar como convergências muito fortes de figuras, de pensamentos, de práticas ou de imaginários sociais constroem, em certos momentos, formas ou grades de leitura do mundo que podem ter sentido para além das sociedades que as produziram. E o outro interesse é, seguramente, avaliar a maneira segundo a qual as singularidades nacionais ou culturais vão variar. Acredito que o modelo do inquérito, por exemplo, que se desenvolve a partir do século XIX, seja muito característico de todo um imaginário ocidental, ao mesmo tempo que é atravessado por singularidades nacionais muito fortes, perceptíveis na maneira segundo a qual ele varia na imprensa, nas práticas policiais ou em outras circulaçóes. É desse duplo interesse que eu acredito que se trata, mas penso realmente em termos de transferências, de histórias cruzadas, de ver como, quando se cruzam problemáticas comuns, pode-se, simultaneamente, generalizar figuras comuns, complexas, epistemológicas, e tornar as singularidades nacionais mais fortemente evidentes.

Topor: Tratando das histórias transnacionais, outra das questôes que circularam muito internacionalmente, entre os países da América Latina, foi a ideia de um modelo francês de polícia, que, felizmente, com a renovação dos estudos históricos sobre a polícia na França, nesses últimos anos, tem sido um pouco questionado, pelo menos em sua rigidez e seu caráter unívoco. Ao mesmo tempo, penso nos trabalhos de Vincent Milliot, nos quais ele disse que há uma nova história da polícia, uma história mais centrada nos atores, onde reconhecemos uma instituição mais complexa, com múltiplos personagens. ${ }^{5}$ Então proliferam histórias dos chefes da polícia, das figuras do prefeito, dos policiais técnico-científicos, dos vigilantes de ruas e, em particular, desta figura central do delegado de polícia, o commissaire. Você editou um livro, uma coletânea de textos, sobre esta figura bastante opaca e tensionada entre diferentes poderes. ${ }^{6}$ Você poderia comentar um pouco essas pesquisas sobre a figura do delegado?

\footnotetext{
${ }^{5}$ MILLIOT, Vincent (Dir.). Les mémoires policiers, 1750-1850. Écritures et pratiques policières du Siècle des Lumières au Second Empire. Rennes: Presses Universitaires de Rennes, 2006; e BERLIERE, Jean-Marc; DENYS, Catherine; KALIFA, Dominique; MILLIOT, Vincent (Dir.). Métiers de police. Être policier en Europe, XVIIIe-XXe siècle. Rennes: Presses universitaires de Rennes, 2008.

${ }^{6}$ KALIFA, Dominique; KARILA-COHEN, Pierre (Dir.). Le commissaire de police au XIXe siècle. Paris: Publications de la Sorbonne, 2008.
} 
D. Kalifa: Eu não sou realmente um historiador da polícia, Vincent Milliot ou Jean-Marc Berlière responderiam a essa pergunta melhor do que eu. Deparei-me frequentemente com a polícia, então me interesso por ela, mas tome minhas respostas com precaução, porque náo sou um especialista dessa área. Parece-me muito importante o movimento que, principalmente sob a iniciativa de Vincent Milliot, se desenha já há algum tempo e que procurou quebrar construçôes muito unívocas de polícia, tanto em termos nacionais como de periodizaçóes. Aceitou-se durante muito tempo, na França, uma espécie de grande corte, segundo o qual a polícia do Primeiro Império teria inventado, a partir de 1800, uma polícia moderna, em ruptura total com as práticas do Antigo Regime. Tem-se percebido, e o trabalho de Vincent Milliot é nesse aspecto muito interessante, que a ruptura não se encontra aí, que as filiaçóes, os reajustamentos são muito importantes. E, quanto ao suposto modelo francês, sabe-se também que, de certa maneira, ele foi grandemente importado da Inglaterra, visto que a ideia fundamental do policial de uniforme foi em Robert Peel que o Segundo Império foi buscá-la, importando, a princípio em 1829 e depois em 1854, a imagem do Bobby, do policial britânico. Acredito, portanto, que é preciso ser muito prudente com essas histórias de "polícia francesa" e que, pelo contrário, se trata efetivamente da necessidade de pensar as experiências e as funçôes policiais. Em relação a isso, o termo que utilizamos no livro é muito importante, as funçóes policiais, que são funçôes extremamente flexíveis, nos quadros de uma sociedade em permanente adaptação. Como demonstrou Paolo Napoli em sua obra fundamental sobre a invenção da polícia, ${ }^{7}$ é preciso pensá-la a partir de contextualizaçôes dotadas de flexibilidade e de adaptabilidade irrestritas. A polícia é precisamente essa instituição que poderá vir a preencher os buracos, se adaptar, se ajustar a necessidades em permanente evoluçáo, o que, portanto, quebra um pouco essa ideia de modelo - modelo francês, modelo inglês - para mostrar que efetivamente estamos em face de um tipo de instituiçáo muito flexível, que responde a uma gama de necessidades muito diversas, muito complicadas, que vão da informação política à prisão cotidiana de criminosos, mas em função de situaçôes que são sempre muito variáveis. $\mathrm{O}$ comissário de polícia é perfeitamente representativo dessa mobilidade, dessa flexibilidade de atividades, visto que, como procurei mostrar com Pierre Karila-Cohen, ele é de fato uma personagem intermediária, sempre preso entre diferentes tipos de poder: o poder da administração policial, o poder municipal, o poder e as demandas dos indivíduos, dos procuradores, das diferentes instituições — a justiça, as instituiçóes políticas —, ao mesmo tempo que ele próprio encarna tipos de poderes diferentes, e que deve, a cada vez, adaptar, ajustar sua ação própria a demandas extremamente diferentes. Então, eu penso sim que saímos de uma leitura institucional, e também modelizadora, da polícia, para mostrar como ela funciona sempre no interior de tipos de ajustamento muito flexíveis a contextos, demandas e missóes extremamente diferentes. $\mathrm{Na}$ França, essa questão se complica ainda mais, devido à existência de uma polícia que foi durante muito tempo esquecida, mas que é atualmente muito estudada por Jean-Noël Luc: a gendarmeria. Ela é uma força ainda mais singular, fundamental, porque é a principal força policial do país, ela acrescenta ainda uma instituição de referência, o exército, visto que a gendarmeria é uma força armada, com uma relação e todo um habitus profissional de militares.

Topor: Ainda em relação a essas questôes, chama a atenção o fato de os policiais sul-americanos que viajavam para Paris na Belle Époque, para analisar esse suposto modelo francês de que tanto se lhes falava, na verdade o acabavam criticando. Por exemplo, criticavam muitíssimo o commissaire, porque tanto em Buenos Aires como no Rio de Janeiro a figura do delegado era central para a polícia e muito ativa. E eles viam o commissaire francês como um personagem fraco, sem poder na rua.

D. Kalifa: Em primeiro lugar, é preciso saber que na França há vários tipos de comissários, que se modificam ao longo do tempo. O tipo principal é, seguramente, o comissário municipal ou o co-

${ }^{7}$ NAPOLI, Paolo. Naissance de la police moderne: pouvoir, norme, société. Paris: La Découverte, 2003. 
missário de bairro em Paris. Náo sei se você leu o livro de John Merriman, Police stories. ${ }^{8}$ Embora um pouco criticável em sua problemática geral, ele mostra bem, a partir de casos particulares muito claros, retirados dos arquivos, que, mesmo que esse comissário de polícia tenha sido efetivamente julgado inoperante, ineficiente, porque preso entre poderes diferentes, destituído de meios, e na maioria dos casos pouco eficaz na luta contra o crime, no plano local ele conseguia reduzir as tensóes, apaziguar os conflitos e assegurar a paz social nas cidades. Ele permaneceu alguém que podia de fato ser uma figura de consenso entre a populaçáo e desempenhar um papel importante nessa aculturaçáo à ordem pública e à ordem policial modernas. Mas na França também ele é muito criticado, considerado sobretudo uma figura arcaica, a do homem em seu escritório, sem condiçôes efetivas de desempenhar suas funçôes. O olhar dos policiais argentinos ou sul-americanos é, portanto, em grande parte compartilhado pelos críticos franceses. Mas eu penso que seja preciso considerá-lo também em relação às expectativas da população; e acredito que, em várias cidades pequenas, o comissário tenha desempenhado perfeitamente o seu papel, porque o que interessava às pessoas era que ele fosse capaz de controlar os preços no mercado local, de fazer circular os imigrantes ou os nômades ou os vagabundos; que ele fosse capaz de aparecer um pouco como essa figura da autoridade familiar, que ia repreender o jovem que tinha roubado ou o alcóolatra que tinha bebido demais. Foi esse caráter, de certo modo, de uma autoridade familiar e a capacidade de apaziguar os conflitos ordinários, em uma escala local, que ele pôde desempenhar. Mas isso náo impediu que ele fosse muito criticado também na França.

Topor: Para terminar, eu lhe perguntaria em que direção suas reflexôes o conduzem atualmente, quais são os seus temas de pesquisa no momento?

D. Kalifa: Entre os motivos da minha imensa admiraçáo por Alain Corbin, que foi meu segundo mestre, está a sua inacreditável capacidade de renovar. Ele inventou o que podemos chamar de história das sensibilidades e uma antropologia histórica das sensibilidades, uma história sensível, mas, ao mesmo tempo, sempre soube renovar, revigorar, redescobrir objetos novos, inesperados. Admiro muito essa capacidade, que está longe de ser a minha; tento, por minha parte, encontrar novas formas de pensar objetos que me são caros. Acabo de fazer um trabalho bem diferente sobre os presídios militares franceses, sobre como o exército francês inventou um espantoso sistema de repressáo e de disciplina no império colonial, essencialmente na África do Norte, e como, também na França, se constituiu toda uma cultura muito tenebrosa do império e do exército, a partir dessa experiência. O que significou conservar objetos que me eram próprios, como a transgressão, a penalidade, a cultura popular, mas também tentar pensá-los em outro campo. ${ }^{9}$ Atualmente procuro refletir a respeito da noção de imaginário social, que me instiga muito - o que é um imaginário social? - e, no cerne dessa noçáo, tenho tentado pensar a imagem do bas-fonds, que defino como sendo, ao mesmo tempo, um estado topográfico — trata-se de um lugar - , um estado social e um estado moral, no qual se conjugariam a extrema pobreza, o "vício" e a transgressão, a criminalidade. Procuro sobretudo compreender como, a partir do final da Idade Média, se constituiu um imaginário muito potente desses bas-fonds, às vezes em relação com realidades econômicas e sociais, às vezes não, mas que não deixou, nas sociedades ocidentais, de constituir um motivo maior, em progressão permanente. E assim eu retomo a questáo das transferências que discutíamos há pouco, porque é considerável a circulação do imaginário do bas-fonds, entre Paris e Londres, mas também entre Paris, Nova York e Chicago, e em seguida entre Paris, Marselha, Argel e entre Paris, Marselha, Buenos Aires e Rio de Janeiro. Em outras palavras, trata-se de analisar a constituição e as circulaçôes desses imaginários. E, sobretudo, de tentar — não sei se o conseguirei — responder a esta

\footnotetext{
${ }^{8}$ MERRIMAN, John M. Police stories: making the French State, 1815-1851. Oxford; Nova York: Oxford University Press, 2006.

${ }^{9}$ KALIFA, Dominique. Biribi. Les bagnes coloniaux de l'armée française. Paris: Perrin, 2009.
} 
questão ambiciosa, que nos afasta um pouco da história, conduzindo de volta ao caminho das estruturas antropológicas evocadas há pouco e que é a seguinte: por que nossas sociedades consomem, em grande quantidade, essas representaçóes do bas-fonds? Por que precisamos atualmente dessas representaçôes, às vezes aterrorizantes, do baixo de nossa sociedade, para pensá-la? Que funçôes desempenham essas representaçóes do baixo em uma sociedade que visa, apesar de tudo, à integração e à representação do excluído? Trata-se de um trabalho, então, muito distinto e muito mais amplo do que aqueles que já fiz sobre a história de um imaginário social, a respeito do qual eu gostaria de conseguir responder a essa questão — muito antropológica — da nossa necessidade de consumo do avesso da sociedade. ${ }^{10}$

${ }^{10}$ KALIFA, Dominique. Les bas-fonds: histoire d'un imaginaire. Paris: Seuil, 2013. 